\title{
Mental Health in COVID-2019 Survivors from a General Hospital in Peru: Sociodemographic, Clinical, and Inflammatory Variable Associations
}

\author{
Jeff Huarcaya-Victoria ${ }^{1,2}$ (D) Jessica Barreto ${ }^{2,3}$ (D) Lucia Aire $^{2}$ (D) \\ Angela Podestá ${ }^{2} \mathbb{D} \cdot$ Mónica Caqui $^{2}$ (D) Rosa Guija-lgreda ${ }^{2} \cdot$ Claudia Castillo $^{2}$. \\ Christoper A. Alarcon-Ruiz ${ }^{4}$ (D)
}

Accepted: 16 September 2021 / Published online: 28 September 2021

(c) The Author(s), under exclusive licence to Springer Science+Business Media, LLC, part of Springer Nature 2021

\begin{abstract}
The current coronavirus disease-2019 (COVID-19) pandemic constitutes a significant public health problem worldwide, as well as mental health problems. This study aimed to evaluate the mental health of COVID-19 survivors, considering their sociodemographic, clinical, and immune variables. A cross-sectional and correlational study was conducted on 318 COVID-19 survivors from one hospital in Peru. Through telephone interviews, evaluation of the presence of depressive symptoms using the Patient Health Questionnaire-9, anxiety symptoms through the Generalized Anxiety Disorder-7, somatic symptoms through Patient Health Questionnaire-15, and posttraumatic stress disorder (PTSD) symptoms through Impact of Event Scale-Revised was carried out. Poisson regression analyses were performed with their adjusted variances to calculate the prevalence ratio (PR) with their 95\% confidence interval. All regression models were adjusted (PRa) for follow-up time. A significant proportion of patients have depressive (30.9\%), anxious (31.1\%), somatic (35.2\%), and PTSD (29.5\%) symptoms. The variables associated with a higher frequency of clinically relevant mental symptoms were female sex, self-perception of greater COVID19 severity, presence of persistent COVID-19 symptoms, loss of a family member due to COVID-19, and prior psychiatric diagnosis or treatment. In addition, the neutrophil-tolymphocyte ratio was significantly higher in patients with clinically relevant symptoms of depression. COVID-19 survivors showed a high prevalence of negative mental symptoms. Our findings help to identify patients who are vulnerable and require psychiatric care.
\end{abstract}

Keywords COVID-19 $\cdot$ Depression $\cdot$ Anxiety $\cdot$ Somatic symptoms $\cdot$ Posttraumatic stress disorder $\cdot$ Inflammation $\cdot$ Peru

The current pandemic of the novel coronavirus disease-2019 (COVID-19), caused by the severe acute respiratory syndrome coronavirus 2 (SARS-CoV-2), represents a significant problem for world mental health (Velavan \& Meyer, 2020). Until August 7, 2021,

Jeff Huarcaya-Victoria

jhuarcaya@usil.edu.pe

Extended author information available on the last page of the article 
200,840,180 confirmed cases and 4,265,903 deaths worldwide were reported (World Health Organization, 2021). During the same period in Peru, one of the countries with the highest mortality per million habitants rate, 2,121,061 confirmed cases and 196,760 deaths were reported with the lethality of $9.28 \%$ (Gobierno del Perú, 2021). The COVID19 pandemic increases the mental health problems of the general population, healthcare workers, patients with COVID-19, and quarantined persons (Wu et al., 2021). In Peru, an increased burden of depressive symptoms and psychosocial reactions has emerged during the COVID-19 pandemic compared to previous years (Antiporta et al., 2021). This mental health burden disproportionately affects women, the younger population, and those with low income and educational levels (Antiporta et al., 20212021).

Previous studies reported that patients with viral respiratory infections, similar to COVID-19, showed varying degrees of mental health problems, such as depression, anxiety, adjustment disorders, acute stress-related disorders, and posttraumatic stress disorder (PTSD), even after disease recovery (Rogers et al., 2020). Hence, research in different countries documented that patients with COVID-19 also experienced the onset or exacerbation of diverse problems in their mental health (Bo et al., 2020; Huarcaya-Victoria et al., 2020; Rogers et al., 2020). Patients with COVID-19 tended to have a high prevalence of adverse psychological events (Wang et al., 2021). This is due to diverse factors from psychosocial problems caused by quarantine, hospitalization, and an invasion of SARS-CoV-2 to the central nervous system or the consequence of the systemic immune response in the form of a "cytokine storm" (Kontoangelos et al., 2020; Raony et al., 2020).

COVID-19 pandemic is a new type of trauma that has never been conceptually or empirically analyzed in mental health and psychiatric research (Kira, et al., 2021a, b). Different factors make COVID-19 a unique trauma type: (a) continuous ongoing traumatic stress, (b) multiple complex trauma, and (c) unnecessarily relationship to the actual infection of COVID-19, but also is more related to the perceived threat of the uncontrolled virus and the direct and indirect social consequences (Kira et al., 2021a, b). This challenged the current paradigms of traumatic stress. Current pathogenic event models focus on past and largely direct trauma exposure to certain kinds of life-threatening events (Bridgland et al., 2021; Kira, 2021). COVID-19 pandemic is understood as a traumatic stressor capable of eliciting PTSD symptoms and exacerbating other mental health problems (Bridgland et al., 2021). COVID-19 continuous PTSD does not fit within the current trauma frameworks; thus, a need arises for a paradigm shift in current stress and trauma frameworks to account for the COVID-19 continuous global stressors and clinical intervention innovations to help its victims (Kira et al., 2021a, b). As evidence of the neurocognitive sequelae of COVID19 emerges, psychological trauma should not be overlooked as an important contributor to the neuropsychological robustness and quality of life of COVID-19 survivors (Kaseda \& Levine, 2020).

When SARS-CoV-2 infects the respiratory tract, an acute respiratory syndrome occurs with the consequent release of proinflammatory cytokines, such as interleukin (IL)-1 $\beta$ and IL-6, producing a "cytokine storm" (Conti et al., 2020). Through their effects on the neurotransmitter systems, cytokines impact neurocircuits in the brain, leading to significant changes in motor activity, motivation, and anxiety (Miller et al., 2013). These neurotransmitter metabolism changes are involved in the pathophysiology of various psychiatric disorders, such as schizophrenia, depression, anxiety, PTSD, and obsessive-compulsive disorder (Bandelow et al., 2017; Grace, 2016; Raony et al., 2020). However, in some circumstances, a study of these cytokines is impossible. Therefore, their increase is indirectly value through elevated various inflammatory parameters with the neutrophil-to-lymphocyte ratio (NLR). This provides a quick and easy way to value the state of systemic 
inflammation, which is calculated from a complete blood count. NLR elevations were associated with increased cytokines, such as IL-6 and IL-8 (Karageorgiou et al., 2019). Elevated NLR reflects a transdiagnostic pathological process occurring in a subpopulation of patients with psychiatric problems (Brinn \& Stone, 2020). Given the relationship between elevated levels of cytokines in COVID-19 as well as in psychiatric disorders, the immune/ inflammatory pathways are considered as one of the mechanisms involved in the mental health problems of this infection (Raony et al., 2020).

The majority of studies about the impact on mental health in patients with COVID19 were conducted in hospital settings using convenience samples, and only one study reported depression and anxiety prevalence for outpatients, which was 35\% and 33\%, respectively (Deng et al., 2020). Moreover, the majority of studies were conducted on the Chinese population since China was the first country affected by the pandemic (Deng et al., 2020). Despite the usefulness of these data, demographic and interindividual characteristics are determining factors in the psychological responses of different populations to a large-scale stressful event such as the current pandemic (Moccia et al., 2020). Hence, to carry out studies that assess the impact of this disease in each of the affected countries, especially in countries like Peru, which was one of the most affected by this pandemic is crucial (Gobierno del Perú, 2021).

Information regarding the impact of this novel pandemic on mental health in patients surviving from COVID-19 is scarce; thus, this study aimed to describe the characteristics of mental health and the main sociodemographic, clinical, and immune factors related to the disease.

\section{Materials and Methods}

\section{Study Design}

This single-center cross-sectional study evaluated the influence of sociodemographic, clinical, and immune characteristics on the levels of depression, anxiety, somatic, and PTSD symptoms in outpatients who survived COVID-19.

\section{Clinical Context}

This study was carried out at Hospital Nacional Guillermo Almenara Irigoyen (HNGAI), which is the second largest hospital of the "Seguridad Social de Salud del Perú" (EsSalud), with a total of 815 hospital beds. Furthermore, it is a tertiary referral hospital with medical specialties. By 2019, the Almenara network met the health needs of 1,634,990 insured (Seguro Social de Salud, 2020). Social security is one of the forms of medical insurance that Peru utilizes; thus, patients treated are those with insurance, whose contribution is paid by the employer. In the case of pensioners, the contribution is charged to the insured. This insurance includes dependent, domestic, civil construction workers, and port, fishermen, and pensioners. EsSalud is financed by the Ministry of Labor (Alcalde-Rabanal et al., 2011).

During the COVID-19 pandemic, HNGAI was a national referral center for the care of patients with COVID-19. Due to the high care demand, hospital beds of different specialties were redistributed to care for patients with COVID-19. Moreover, new hospital 
environments were created. COVID-19 diagnoses were made with serological tests, which were later confirmed with molecular tests.

According to EsSalud's records, from the beginning of the pandemic until September 2020, in HNGAI, a total of 3238 patients diagnosed with COVID-19 were discharged. For this study, minors $(n=369)$, deceased $(n=843)$, referred to another center $(n=88)$, and voluntary discharge $(n=14)$, as well as those patients with two or more hospitalizations during March to September $2020(n=14)$, were excluded. Hence, patients who were discharged from the hospital $(n=1910)$ were only considered.

\section{Participants}

The sample was obtained from a population of 1910 patients with COVID-19 who were discharged from HNGAI services between March and September 2020. The Paz et al. study (Paz et al., 2020) was used to calculate the sample size. In this study, an expected frequency of 55\% of mental health problems in patients with COVID-19 was estimated. Considering a margin error of $5 \%$ with this data, with a design effect of 1 and a single group, a total of 318 individuals with a $95 \%$ confidence interval (CI) were obtained.

The sample was selected through a simple random sampling using the Epidat v4.2 program (Dirección Xeral de Saúde Pública da Consellería de Sanidade, Galicia, España). Each of the 1910 patients had a coding.

Variables were collected in a virtual file through telephone calls to patients between October 22 and November 28, 2020. The cell phone number that was registered in the electronic medical record of each patient was used. Calls were made by the co-investigators, who are psychiatrists with clinical and research experience. Participants who did not answer after two calls were excluded from the study $(n=112)$, and a new participant is randomly selected. In addition, a group of selected participants did not wish to continue with the interview $(n=8)$. Therefore, they were removed from the database, and new participants were randomly selected (Fig. 1).

\section{Measures}

\section{Depression}

The Patient Health Questionnaire-9 (PHQ-9) was used to evaluate depressive symptoms. This scale consists of 9 items that evaluated the frequency of depressive symptoms in the previous 2 weeks, which are rated on a Likert scale ranging from 0 ("not at all") to 3 ("nearly every day"). The PHQ-9 scores reflect 5 categories of severity of depressive disorders: None (0-4), mild (5-9), moderate (10-14), moderately severe (15-19), and severe (20-27). In studies carried out in Latin America, PHQ-9 was proven as a valid and reliable tool to detect depressive symptoms in various types of populations (Cassiani-Miranda et al., 2017; Saldivia et al., 2019). Furthermore, PHQ-9 was validated in Peru. Validity indicators include internal structure, measurement invariance, and acceptable internal consistency values (Villarreal-Zegarra et al., 2019).

\section{Anxiety}

Generalized Anxiety Disorder-7 (GAD-7) was used as a valid and efficient scale to assess the severity of anxiety disorders in clinical practice and investigation (Spitzer 


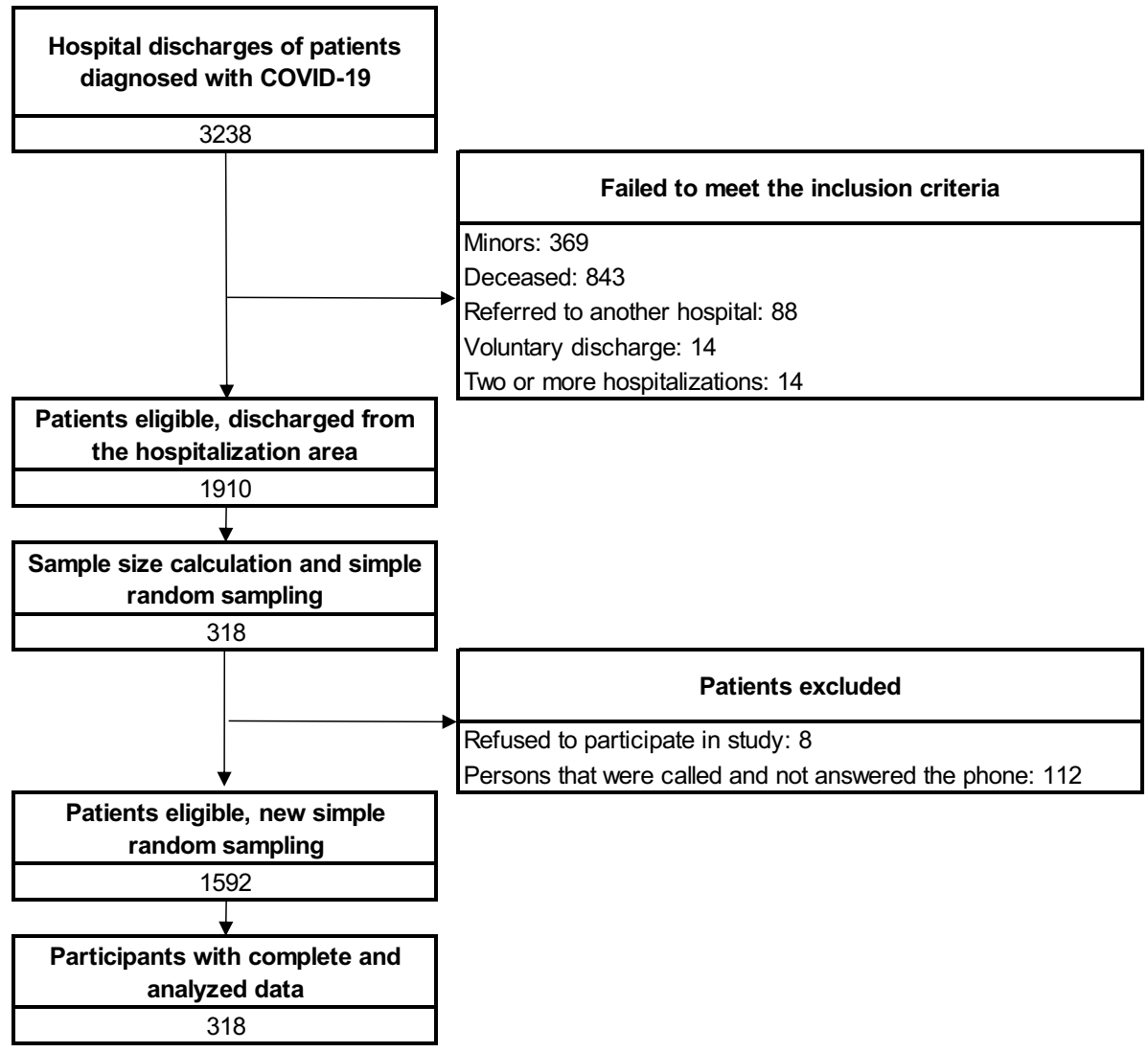

Fig. 1 Selection flowchart

et al., 2006). The scale consists of 7 items that evaluate the anxiety symptomatology during the 2 weeks before the scale application. Each item is rated according to a Likert scale ranging from 0 ("not at all") to 3 ("nearly every day"). GAD-7 reflects 4 categories of severity of the anxiety disorder: none (0-4), mild (5-9), moderate (10-14), and severe anxiety (15-21). This scale was translated into Spanish and was validated (Garcia-Campayo et al., 2010).

\section{Somatic Symptoms}

The Patient Health Questionnaire-15 (PHQ-15) was used to evaluate somatic symptoms. It consists of 15 items related to 15 possible somatic symptoms that bothered the patient during the previous 4 weeks (Kroenke et al., 2002). Each item is rated as: "nothing" or absence of the problem ( 0 points), "a little" or presence of the problem (1 point), or "a lot" or high presence of the problem (2 points). The PHQ-15 scores reflect 4 categories of severity of somatic symptoms: none (0-4), mild (5-9), moderate (10-14), and severe (15-30). This scale was translated into Spanish and was validated (Ros Montalbán et al., 2010). 


\section{PTSD Symptoms}

The Impact of Event Scale-Revised (IES-R) was used to evaluate PTSD symptoms (Weiss \& Marmar, 1997). This scale measures the degree of suffering caused by a life event (for this study, the hospitalization of COVID-19 was considered as a stressful event), which is conceptualized as a form of subjective stress. IES-R consists of 22 items: 7 assessed intrusion symptoms, 8 avoidance, and 7 hyperarousal (Caamaño W et al., 2011). It is rated according to the Likert scale ranging from 0 ("not at all") to 4 ("extremely"). The IES-R scores reflect 5 categories of PTSD symptom severity: none (0-8), mild (9-25), moderate (26-43), and severe (44-88). This scale was translated into Spanish and was validated (Caamaño W et al., 2011).

\section{Further Variables}

Information regarding the following variables was collected: (a) sociodemographic data, including sex, age, educational degree, job status, place of origin before hospitalization, current place of residence, with whom they live, history of relative infected, and/or deceased due to COVID-19; (b) clinical and hospitalization data, including diagnosis and/ or treatment history for psychiatric diagnosis, self-perception of COVID-19 severity, hospitalization area, hospitalization duration, days from discharge to the interview (followup time), presence of COVID-19 symptoms during the interview; and (c) immune data, including NLR and monocyte-to-lymphocyte ratio (MLR) at the beginning of hospitalization. Immune variables were obtained by reviewing electronic medical records.

\section{Statistical Analyses}

All data analysis followed the random sampling design and used survey data analysis. The general weight of 6.0062893 and the finite population correction of 1910 were considered. In addition, post-stratification weights by the "Hospitalization area" variable were applied for a better sampling adjustment (Kreuter \& Valliant, 2007). The relative and absolute frequency of the categorical variables was described. For quantitative variables, the mean and 95\% CI are described. Then, the four outcome variables of mental health: depression, anxiety, somatic, and PTSD symptoms were dichotomized as clinically irrelevant (none-mild) and clinically relevant (moderate-severe). Consequently, the hospitalization time was categorized into 1-7 days, 8-14 days, and $>14$ days. In the dichotomous analysis, the association between each covariate with each dichotomized mental health outcome variable was evaluated. Chi-2 test was used for categorical covariates and Student's $T$ test was used for numerical covariates.

Before the regression analysis, the age variable was categorized into quartiles. Additionally, the NLR was categorized as $<6.5$ and $\geq 6.5$ (Li et al., 2020), and the MLR was categorized as $<0.364$ and $\geq 0.364$ (Fois et al., 2020). The cut-off points were chosen considering their ability to predict in-hospital mortality in patients with COVID-19. The COVID-19 symptom variable at admission and during the interview was categorized into asymptomatic (without any symptoms during the follow-up) and symptomatic (at least one symptom during the follow-up).

Poisson regression analyses were performed with their adjusted variances to calculate the prevalence ratio (PR) with their 95\% CI. All regression models were adjusted (PRa) for follow-up time. An epidemiologic approach was considered using direct acyclic graphs 
for clinical (self-perception of severity and persistent COVID-19 symptoms) and laboratory covariables (NLR and MLR upon admission). The regression model of the covariate "self-perception of COVID-19 severity" was adjusted for COVID-19 symptoms at the moment of admission to hospitalization and during the interview. The regression models for the covariates "NLR at admission" and "MLR at admission" were also adjusted for the self-perception of COVID-19 severity. Finally, the regression model for the covariate of "COVID-19 symptoms during the interview" was adjusted for follow-up time, presence of COVID-19 symptoms at admission, and self-perception of COVID-19 severity. A $p$ value of $<0.05$ was considered statistically significant. Stata MP v.16.0 statistical software was used for all analyses.

\section{Ethical Aspects}

Verbal informed consent was obtained from each participant. This included an explanation of the objectives of the investigation, as well as the rights of the participants (anonymity and the right to refrain from participating as considered appropriate). Furthermore, psychiatric help was offered when the interviewer considered it necessary at some point, either during or after the phone interview. This investigation was carried out with the authorization of EsSalud's Research Ethics Committee Specific to COVID-19.

\section{Results}

In a representative sample of COVID-19 survivors, the majority were men (61.3\%), professed religion $(92.7 \%)$, were from Lima (94.5\%), with an average age of 53.1 years, lived with a partner and/or children (79.8\%), had at least one family member infected $(82.7 \%)$, and at least one relative died (30.4\%) due to COVID-19. Survey respondents perceived their COVID-19 disease as severe accounting for $31.2 \%$, whereas $32.6 \%$ perceived it as moderate. The mean NLR was 8.8 (95\% CI, 8.0-9.7), whereas the MLR was 0.4 (95\% CI, 0.4-0.4). Regarding the COVID-19 symptoms, $8.3 \%$ of the survey respondents were asymptomatic during hospital admission, and 39.4\% were asymptomatic during the interview. The mean time of hospitalization was 11.3 days (95\% CI, 10.2-12.4). Hospitalization time was correlated with the self-perceived severity of the COVID-19 disease. Those who self-perceived a mild COVID-19 disease had a mean hospitalization time of 6.5 days (95\% CI, 5.2 to 7.7). While those who self-perceived a severe and critical-ill COVID19 disease had 14.8 days (95\% CI, 12.4 to 17.1 ) and 26.3 days (95\% CI, 20.7 to 32.0) of mean hospitalization time, respectively. The mean follow-up time was 102.1 days (95\% CI, 98.3-106.0).

This study revealed that $30.9 \%$ of patients had some type of depressive, $31.1 \%$ had anxious, $35.2 \%$ had somatic, and $29.5 \%$ had PTSD symptoms. Regarding the clinically relevant symptoms (moderate-severe), $10.7 \%$ were depressive, $7.6 \%$ anxious, $14.5 \%$ somatic, and $8.2 \%$ PTSD. The rest of the characteristics are described in Table 1.

In the bivariate analysis, women had a higher frequency of clinically relevant symptoms (moderate-severe) of depression $(p=0.011)$, anxiety $(p=0.007)$, somatic $(p=0.013)$, and PTSD $(p=0.071)$. Patients with a history or treatment of psychiatric illness presented a higher frequency of clinically relevant mental symptoms $(p<0.05)$. Those patients who self-reported severe or critical COVID-19 had a higher frequency of clinically relevant depressive $(p=0.004)$ and PTSD symptoms $(p=0.001)$. NLR, in its numerical nature, was 
Table 1 Sample characteristics $(n=318)$

\begin{tabular}{|c|c|}
\hline Characteristics & $n(\%)$ \\
\hline Male & $196(61.3)$ \\
\hline Age (years)* & $53.1(51.8-54.4)$ \\
\hline \multicolumn{2}{|l|}{ Educational degree } \\
\hline None or incomplete & $42(13.3)$ \\
\hline Secondary school & $135(42.6)$ \\
\hline Technical degree & $34(10.3)$ \\
\hline University & $107(33.8)$ \\
\hline \multicolumn{2}{|l|}{ Job status } \\
\hline Unemployed & $95(30.5)$ \\
\hline Informal employment & $31(9.2)$ \\
\hline Formal employment & $143(45.5)$ \\
\hline Retired & 49 (14.8) \\
\hline \multicolumn{2}{|l|}{ Live with } \\
\hline Alone & $17(5.1)$ \\
\hline Couple and/or children & $256(79.8)$ \\
\hline Parents and/or other family members & $45(15.1)$ \\
\hline Family member infected with COVID-19 & $264(82.7)$ \\
\hline Loss of a family member due to COVID-19 & $97(30.4)$ \\
\hline History of psychiatric diagnosis & $32(10.4)$ \\
\hline History of psychiatric treatment & $27(8.7)$ \\
\hline \multicolumn{2}{|l|}{ Self-perception of COVID-19 severity } \\
\hline Mild & $89(29.1)$ \\
\hline Moderate & $107(32.6)$ \\
\hline Severe & $99(31.2)$ \\
\hline Critically ill & $23(7.0)$ \\
\hline \multicolumn{2}{|l|}{ Hospitalization area } \\
\hline Cardiology & $239(68.9)$ \\
\hline Internal medicine & $35(15.9)$ \\
\hline High-risk obstetrics & $32(10.8)$ \\
\hline Neurology & $12(4.4)$ \\
\hline \multicolumn{2}{|l|}{ Time of hospitalization } \\
\hline 1-7 days & $154(48.4)$ \\
\hline $8-14$ days & $84(26.4)$ \\
\hline$>14$ days & $80(25.2)$ \\
\hline \multicolumn{2}{|l|}{ Depressive symptoms } \\
\hline None & $222(69.0)$ \\
\hline Mild & $62(20.2)$ \\
\hline Moderate & $18(5.6)$ \\
\hline Moderate-severe & $11(3.7)$ \\
\hline Severe & $5(1.4)$ \\
\hline \multicolumn{2}{|l|}{ Somatic symptoms } \\
\hline None & $210(64.9)$ \\
\hline Mild & 65 (20.7) \\
\hline Moderate & $36(12.1)$ \\
\hline Severe & $7(2.4)$ \\
\hline
\end{tabular}


Table 1 (continued)

\begin{tabular}{ll}
\hline Characteristics & $n(\%)$ \\
\hline Anxious symptoms & \\
$\quad$ None & $223(68.9)$ \\
Mild & $71(23.5)$ \\
Moderate & $17(5.4)$ \\
Severe & $7(2.2)$ \\
PTSD symptoms & \\
None & $227(70.5)$ \\
Mild & $66(21.3)$ \\
Moderate & $18(5.8)$ \\
Severe & $7(2.4)$ \\
NLR $\geq 6.5$ at income $(n=277)$ & $135(48.1)$ \\
MLR $\geq 0.364$ upon admission $(n=277)$ & $112(40.4)$ \\
\hline
\end{tabular}

\footnotetext{
*Mean and $95 \%$ confidence intervals

$N L R$ neutrophil-to-lymphocyte ratio,

$M L R$ monocyte-to-lymphocyte ratio,

$P T S D$ posttraumatic stress disorder
}

significantly higher in the clinically relevant symptoms (moderate-severe) of the depressive type compared to that of the clinically irrelevant (11.4, 95\% CI, 8.8-14.1 vs. $8.52,95 \%$ CI, 7.62-9.42; $p=0.041)$. Further associations can be found in Table 2.

In the regression analysis, women have a higher frequency of clinically relevant symptoms of depression ( $\mathrm{PRa}=2.11 ; 95 \% \mathrm{CI}, 1.16-3.84)$, anxiety $(\mathrm{PRa}=2.70 ; 95 \% \mathrm{CI}$, 1.31-5.57), and somatic ( $\mathrm{PRa}=1.90 ; 95 \% \mathrm{CI}, 1.14-3.18)$. Contrarily, patients with a family member infected or who died due to COVID-19, or those with a history of psychiatric diagnosis, have a higher frequency of developing adverse mental health outcomes. Patients who self-reported having severe or critical COVID-19 are more likely to have clinically relevant depression, anxiety, somatic, and PTSD symptoms, compared to those who selfreported a mild infection. No association was found between the NLR ( $\geq 6.5)$ and MLR $(\geq 0.364)$ with adverse mental health outcomes. Lastly, patients with persistent COVID-19 symptoms during the interview were more likely to have a higher frequency of clinically relevant symptoms of depression ( $\mathrm{PRa}=7.80 ; 95 \% \mathrm{CI}, 2.16-28.15)$, somatic (PRa $=6.17$; 95\% CI, 2.48-15.35), anxiety (PRa $=11.50 ; 95 \% \mathrm{CI}, 3.07-43.15)$, and PTSD (PRa = 17.84; 95\% CI, 2.07-153.58) (Table 3).

\section{Discussion}

\section{Main Findings and Meaning of the Results}

This study sought to describe the characteristics of mental health in Peruvian patients surviving from COVID-19, as well as the main related sociodemographic, clinical, and immune factors. In our study, the number of female patients is less than that of males. Similar trends were reported in other studies (Mertz Schou et al., 2021). These results probably relate to gender differences in the infection and admission rates (Gomez et al., 2021). Mental symptoms were present after an average of 100 days after patient discharge. A previous 


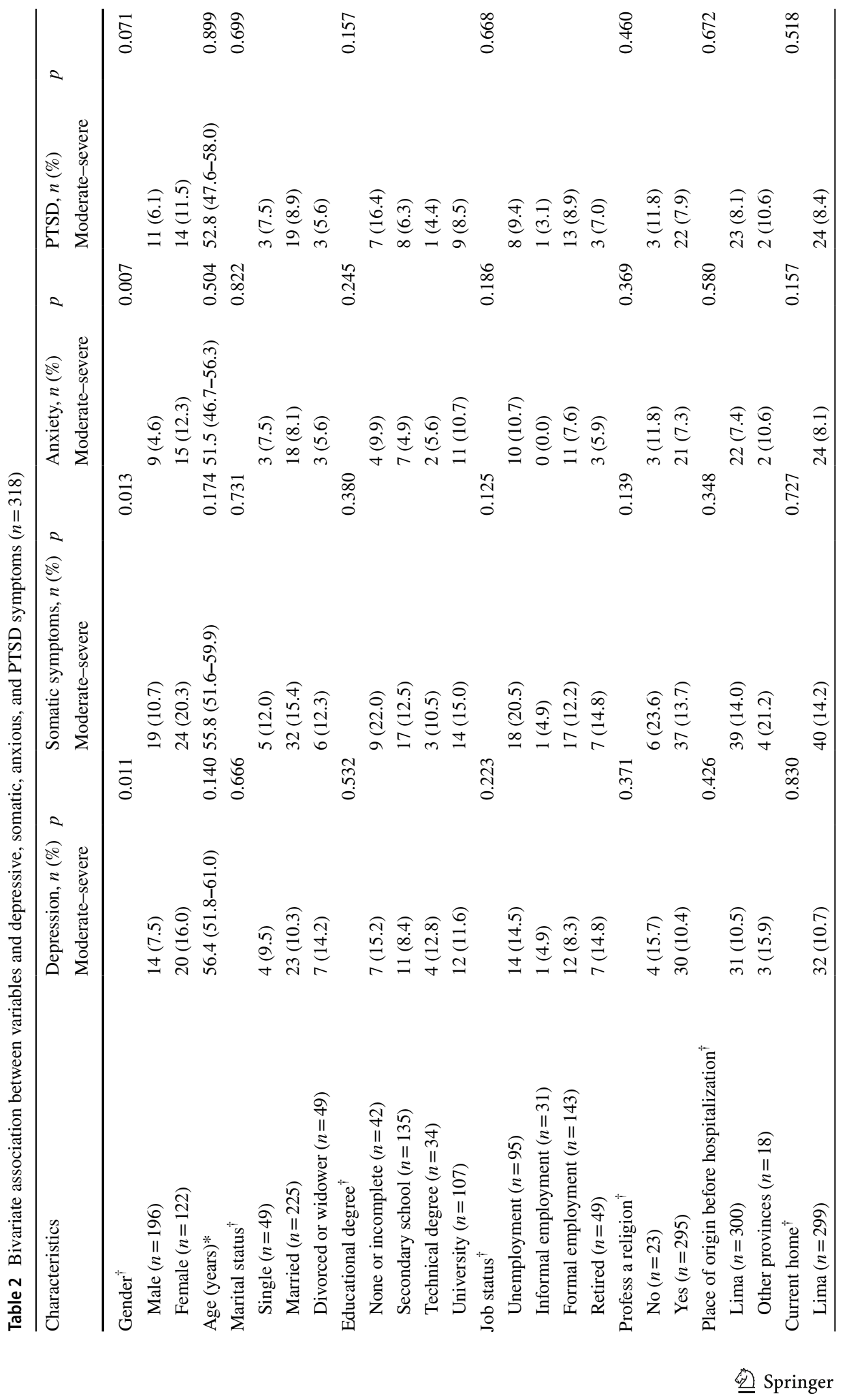




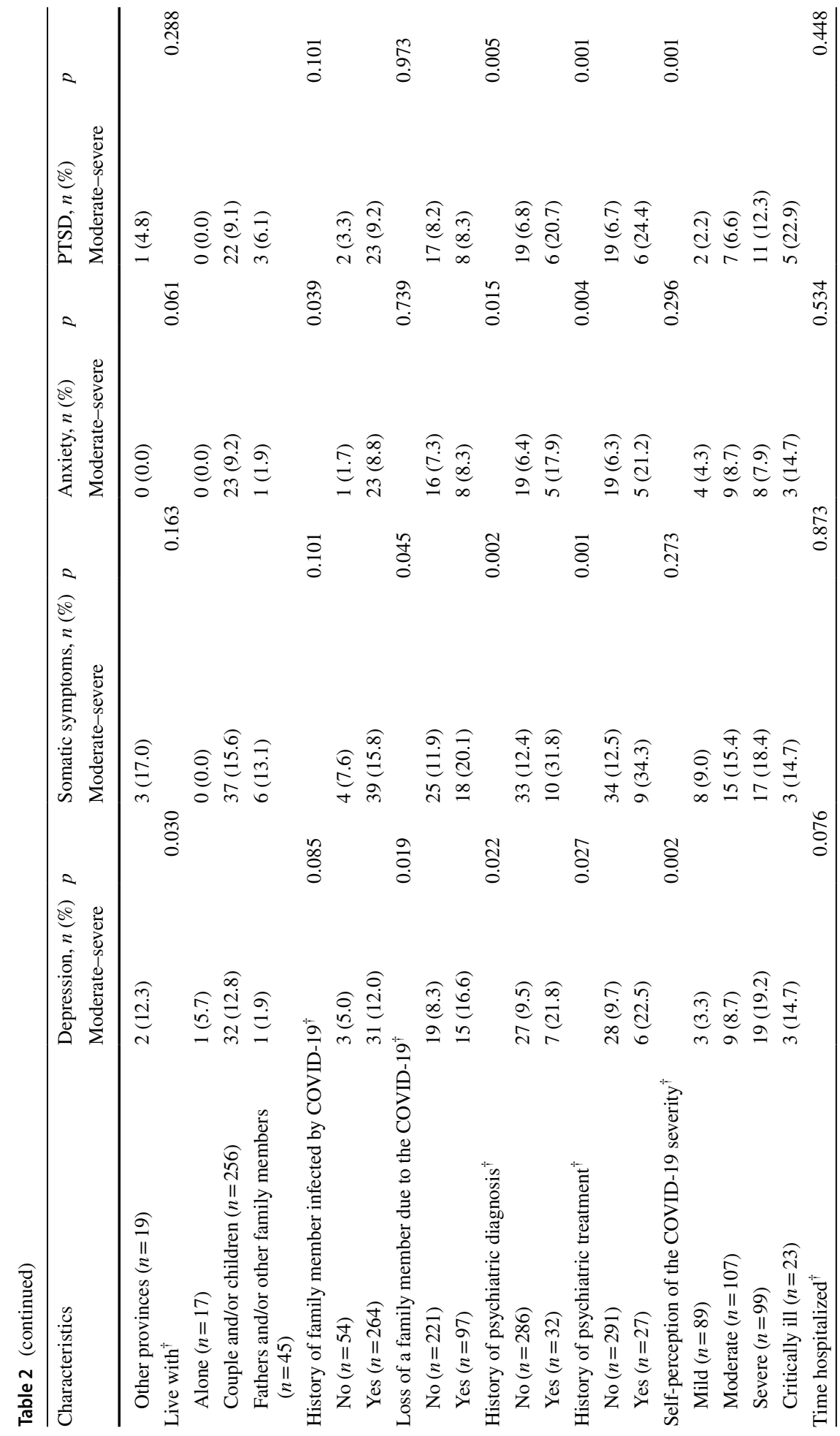




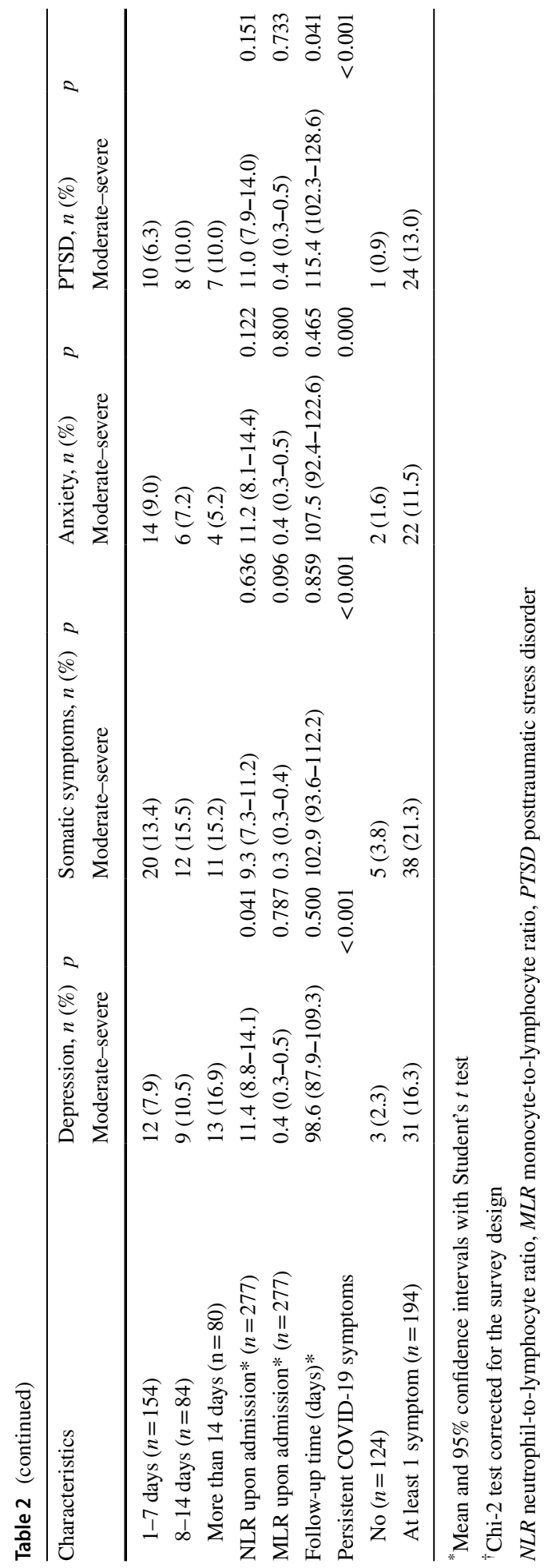




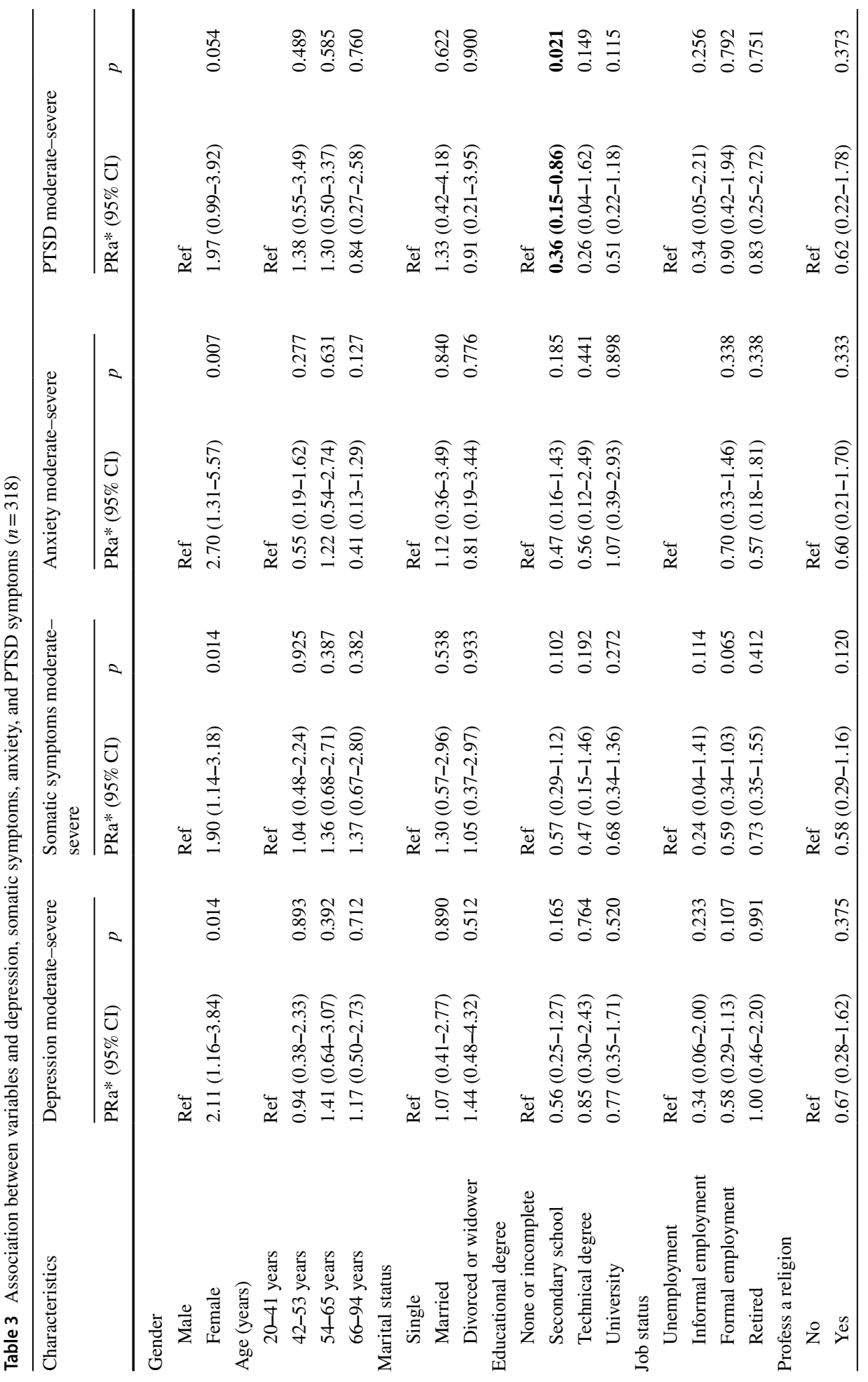




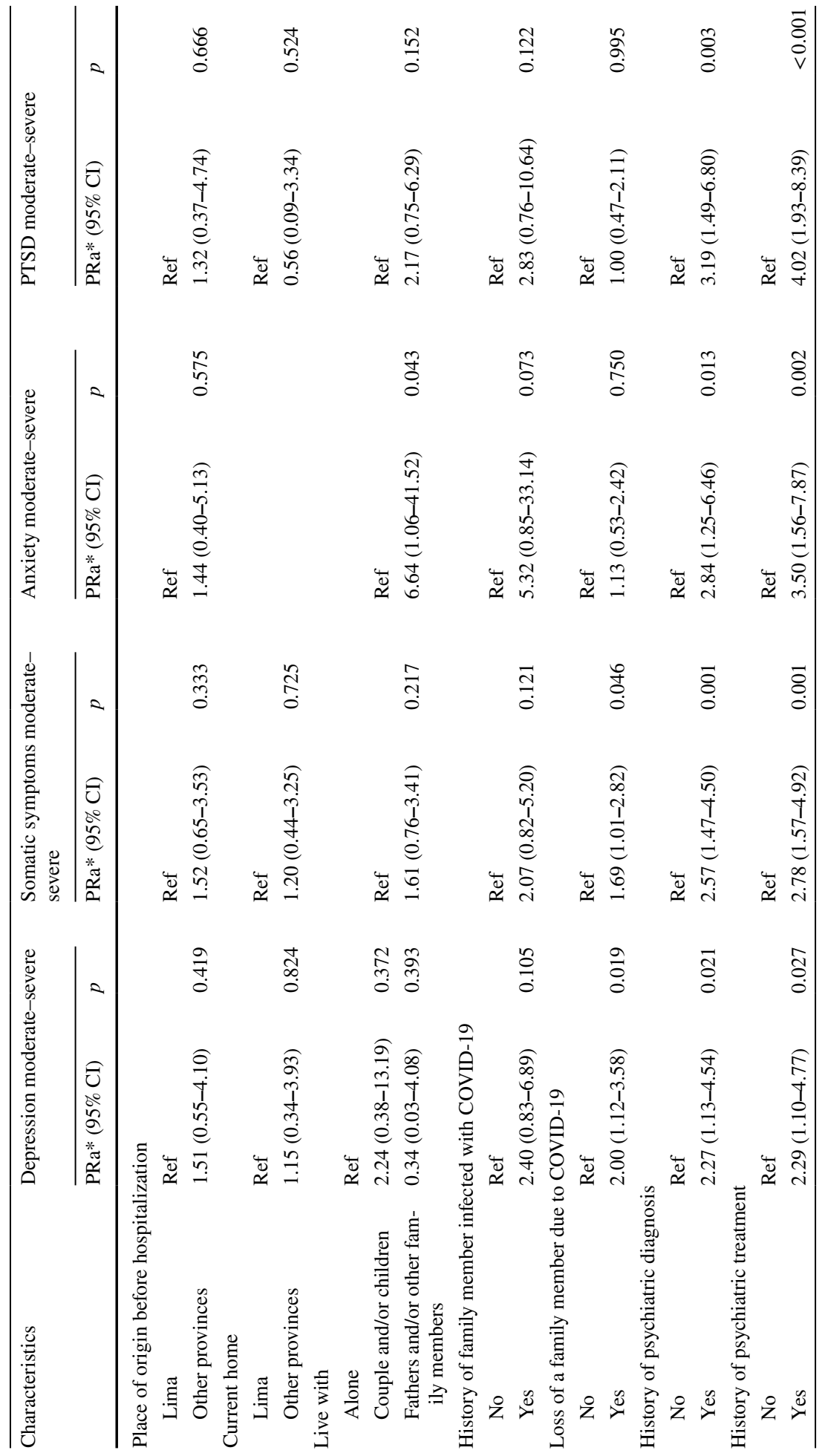




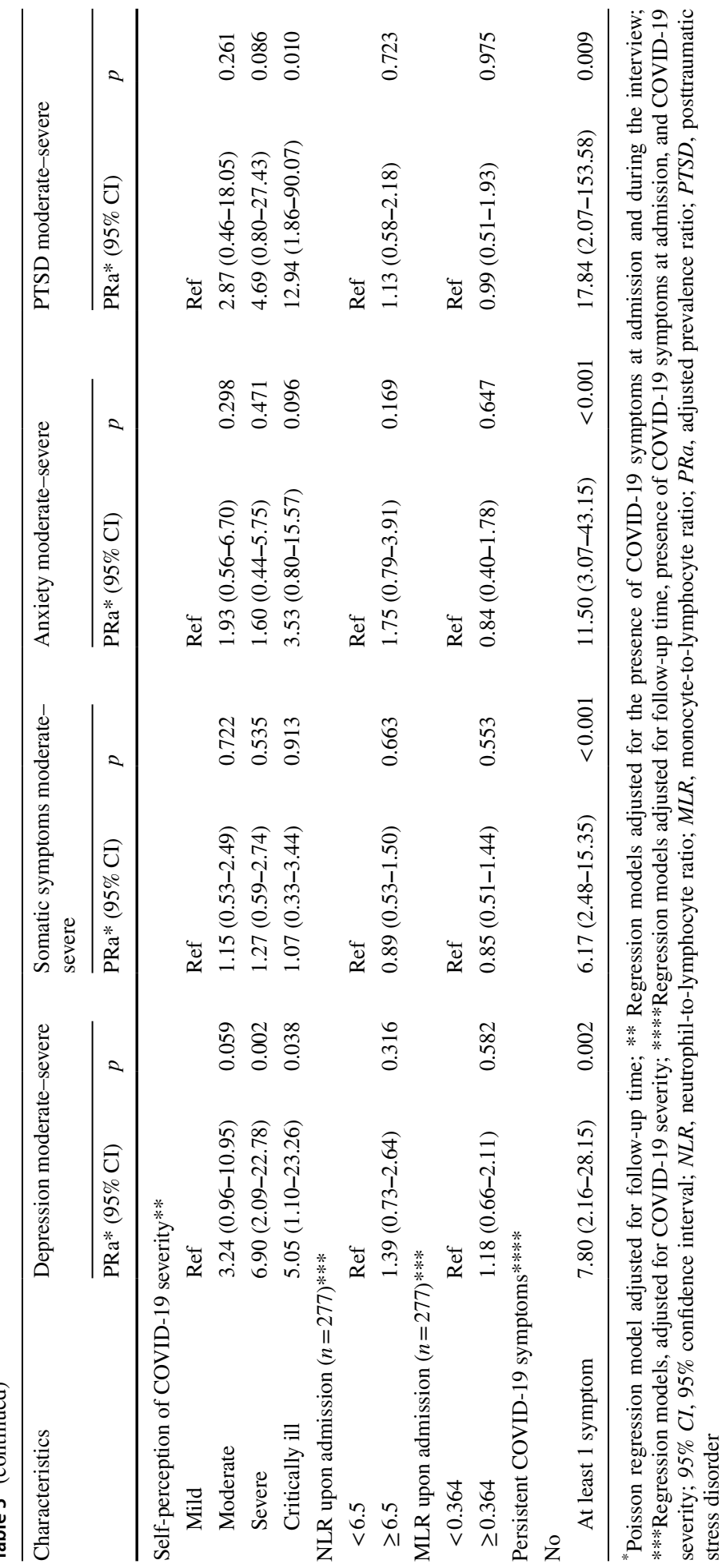


respiratory infection epidemic in South Korea reported that mental symptoms are present for up to a year after the epidemic outbreak (Park et al., 2020). In addition, a cohort study revealed a prevalence of any psychiatric disorder at 30 months post-SARS outbreak of 33.3\% (Mak et al., 2009).

The reported prevalence of depressive (30.9\%) and anxious (31.1\%) symptoms in COVID-19 survivors is similar to the reports in other studies that included patients with mild COVID-19 (Ma et al., 2020; Zhang et al., 2020). Notwithstanding, a recent metaanalysis documented a prevalence of depression of $52 \%$ and anxiety of $47 \%$ (Deng et al., 2020), which is higher than that in our study since most of the included studies were conducted in a hospital setting. An alternative explanation is that the meta-analysis included patients from the early stages of the pandemic (January-March 2020), during which the fear regarding the disease was likely more heightened compared to the current study. The mentioned meta-analysis also reported that depression and anxiety prevalence was lower in outpatients (35\% and 33\%, respectively) compared to hospitalized patients (48\% and $42 \%$, respectively) (Deng et al., 2020). However, only one study was included in the outpatient subgroup; thus, the outpatient population was not truly represented.

The prevalence of clinically relevant depressive symptoms (moderate-severe) (10.7\%) reported in this study is higher than that of the Peruvian population before the pandemic, in which a prevalence of $6.4 \%$ was reported using the PHQ-9 (HernándezVásquez et al., 2020). Therefore, COVID-19 infection impacts the mental health of the Peruvian population by increasing the prevalence of clinically relevant depressive symptoms.

A high prevalence of PTSD symptoms (29.5\%) was found. Data presented by Dawra et al. showed different patterns in 101 patients who are newly diagnosed with COVID-19; using the IES-R, respondents suffered severe (30.7\%), moderate (18.8\%), mild (19.8\%), and minimal (30.7\%) PTSD symptoms (Dawra et al., 2021). In a systematic review for psychiatric sequelae in patients with COVID-19, PTSD results ranged from $6.5 \%$ to $42.8 \%$. Of potential risk factors, PTSD was most pronounced after intensive care unit admission, previous psychiatric history or past traumatic events increased the risk of PTSD, and depressive and anxiety symptoms during acute COVID-19 was a predictor of PTSD (Mertz Schou et al., 2021).

Regarding the somatic symptoms (35.3\%), collected data are consistent with Lee et al., who found that somatic symptoms were more frequent in patients with COVID-19. In another study carried out in the general population in China during the peak of the pandemic, researchers found a prevalence of $45.9 \%$ of somatic symptoms (Ran et al., 2020), higher than that of our study. These symptoms are directly related to COVID-19 infection or occur because of psychological distress (Lee et al., 2021). Physical symptoms, such as fatigue and shortness of breath, occur even after very mild COVID-19 infection in the outpatient setting, making it harder for COVID-19 survivors to return to their work and normal life, and posing major medical, social, and economic challenges (Augustin et al., 2021; Lee et al., 2021).

\section{Variables Associated with Mental Symptoms}

Some sociodemographic variables had a relation to a higher prevalence of clinically relevant mental symptoms. Gender (female) is one of the main variables, which is similar to what was reported in other studies (Guo et al., 2020; Hu et al., 2020; Ma et al., 2020; Mazza et al., 2020; Paz et al., 2020) since women tend to have greater symptoms 
of hyperactivity, recurrent distressing memories, and negative cognitive and mood disturbances (Liu et al., 2020).

Patients with family members who were diagnosed and died of COVID-19 had a higher prevalence of somatic and anxious symptoms. This finding was reported in other studies in China (Nie et al., 2020; Zhang et al., 2020). Specifically, in a study carried out in Wuhan in patients with COVID-19, family members diagnosed and/or deceased with the same disease were independent predictors of the depression severity index, as well as presenting higher anxiety scores (Nie et al., 2020). Likewise, a history of psychiatric diagnosis and treatment was associated with a higher frequency of clinically relevant mental symptoms in COVID-19 survivors since the current pandemic causes reactive symptoms such as stress, depression, and anxiety, which in combination with hospitalization, can aggravate the mental health of people with a previous psychiatric diagnosis (Yao et al., 2020).

Self-perception regarding a greater COVID-19 severity was a variable associated with a higher prevalence of mental symptoms in survivors. A study carried out in patients admitted due to COVID-19 in Wuhan reported a similar result since the patients' concerns about their disease are added to their psychological burden, which is associated with anguish and a poor result in their mental health (Hu et al., 2020). Similarly, another study from Turkey reported that perception of COVID-19 severity was associated with the risk of having PTSD symptoms; however, this association became nonsignificant after controlling the effects of other variables (Poyraz et al., 2020).

A high frequency of persistent COVID-19 symptoms (61\%) was found. This is a similar finding to a study conducted in Chinese patients who survived COVID-19, where it was found that up to $76 \%$ of patients reported at least one COVID-19 symptom after 6 months of follow-up (Huang et al.). The persistence of these symptoms was associated with a higher prevalence of mental symptoms.

\section{Role of the Immune System in Mental Symptoms}

The NLR was significantly higher in patients with clinically relevant symptoms of depression. In a study conducted in patients who survived from COVID-19, researchers found that those who reported depressive symptoms showed a greater immune response evidenced by a higher mean of NLR in their convalescent phase (2.4 vs. $1.8 ; p<0.001)$ (Yuan et al., 2020). Another study from China conducted on admitted patients with COVID-19 revealed that those with mental symptoms have higher levels of IL $1 \beta$ and NLR and lower levels of IL-10 and lymphocyte count (Hu et al., 2020). Thus, COVID-19 infection resulted in prolonged systemic inflammation that predisposes patients to persistent depression (Gennaro et al., 2021).

Considering the impact of COVID-19 infection on mental health and the involvement of the immune system, evaluating the psychopathology of COVID-19 survivors is necessary. Consequently, the investigation of inflammatory biomarkers should be deepened to adequately diagnose, treat, and monitor emerging psychiatric conditions (Mazza et al., 2020). Nonetheless, related biological factors (such as advanced age, female sex, and excess fat), along with other factors inherent to COVID-19 (such as social isolation, financial stress, and adverse effects of treatment) can influence psychiatric outcomes should be considered. As a consequence, the psychiatric symptoms in patients with COVID-19 are due to a combination of the processes involved in the virus-host relationship and the psychosocial and therapeutic problems associated with the pandemic and the disease (Raony et al., 2020). 


\section{Implications for Public Health and Decision-making}

This study evidences a high impact on the mental health of COVID-19 survivors. Hence, Peruvian Public Health must focus on the early diagnosis and treatment of the mental health problems of these patients. All factors that influence these problems, including sociodemographic, proper clinical, and immune factors, should be evaluated. This allows healthcare professionals to establish individual management to improve the psychological well-being of the survivors.

Moreover, implementing health policies that aim to implement diverse mental health services is suggested. These policies include screenings with standardized online evaluations, educational interventions in mental health, provision of psychological support after vulnerable patient detection, systemic inflammation assessment using a complete blood count, and adequate psychiatric care for mental health management. All of these measures will empower Peru in the containment and future eradication of the COVID-19 pandemic (Huarcaya-Victoria, 2020).

\section{Strengths and Limitations of the Study}

Strengths of this study include the sample size and the fact that a random sample was made. Furthermore, to our knowledge, the study provides first-time exploratory data on different factors associated with mental health problems in patients that survived COVID-19 in Peru during a follow-up.

Notwithstanding, this study must be understood in the context of its methodological limitations; since the study is cross-sectional, causal relationship evaluation and evolution of different mental health outcomes from hospital discharge to the moment of evaluation were not achieved. Future studies should evaluate the modification of anxiety, depression, and PTSD levels as the pandemic evolve in Peru. Since we only evaluate patients from one single hospital, results are not generalized to all patients from other hospitals. Further, our results were not compared to control groups, making it difficult to differentiate between direct and indirect effects of the COVID-19 pandemic. Regarding the measurement instruments, the IES-R for DSM-IV, which is a measure for PTSD based on the old version of DSM was used in this study. An additional bias must be considered relating to an erroneous classification of participants, as the validated self-administered tests do not substitute an individualized evaluation performed by a mental health specialist. Finally, because a self-administered scale was used, the risk of different types of biases, such as social desirability is present. Nonetheless, our findings are in line with the reports from other countries.

\section{Conclusions}

Study results indicated a high prevalence of mental symptoms in COVID-19 survivors from a third-level hospital in Peru. Female sex, self-perception of greater COVID-19 severity, presence of persistent COVID-19 symptoms, loss of a family member due to COVID19 , and prior psychiatric diagnosis or treatment were associated with a higher prevalence of clinically relevant mental symptoms. In addition, the NLR was significantly higher in patients with clinically relevant symptoms of depression. All these variables were useful in identifying vulnerable patients who require timely psychiatric care. 
Author Contributions Jeff Huarcaya-Victoria: Conceptualization, investigation, project administration, supervision, and manuscript drafting, review, and editing.

Jessica Barreto: Conceptualization, investigation, data collection, supervision, manuscript drafting, review, and editing.

Lucia Aire: Data collection, review, and manuscript editing.

Angela Podestá: Data collection, review, and manuscript editing.

Mónica Caqui: Data collection, review, and manuscript editing.

Rosa Guija-Igreda: Data collection, review, and manuscript editing.

Claudia Castillo: Data collection, review, and manuscript editing.

Christoper A. Alarcon-Ruiz: Data cleaning, methodology, statistical analysis, review, and manuscript editing.

Funding Self-financing.

\section{Declarations}

Ethics Approval and Consent to Participate This study was approved by the Research Ethics Committee Specific for COVID-19 of the "Seguro Social del Perú" (EsSalud). Informed consent was obtained from each participant for study participation.

Conflict of Interest The authors declare no competing interests.

\section{References}

Alcalde-Rabanal, J. E., Lazo-González, O., \& Nigenda, G. (2011). Sistema de salud de Perú. Salud pública Méx, 53(Supl 2), s243-s254.

Antiporta, D. A., Cutipé, Y. L., Mendoza, M., Celentano, D. D., Stuart, E. A., \& Bruni, A. (2021). Depressive symptoms among Peruvian adult residents amidst a National Lockdown during the COVID-19 pandemic. BMC Psychiatry, 21(1), 111. https://doi.org/10.1186/s12888-021-03107-3

Augustin, M., Schommers, P., Stecher, M., Dewald, F., Gieselmann, L., Gruell, H., . . Lehmann, C. (2021). Post-COVID syndrome in non-hospitalised patients with COVID-19: A longitudinal prospective cohort study. Lancet Reg Health Eur, 6, 100122. https://doi.org/10.1016/j.lanepe.2021.100122

Bandelow, B., Baldwin, D., Abelli, M., Bolea-Alamanac, B., Bourin, M., Chamberlain, S. R., . . Riederer, P. (2017). Biological markers for anxiety disorders, OCD and PTSD: A consensus statement. Part II: Neurochemistry, neurophysiology and neurocognition. World J Biol Psychiatry, 18(3), 162-214. https://doi.org/10.1080/15622975.2016.1190867

Bo, H. X., Li, W., Yang, Y., Wang, Y., Zhang, Q., Cheung, T., . . . Xiang, Y. T. (2020). Posttraumatic stress symptoms and attitude toward crisis mental health services among clinically stable patients with COVID-19 in China. Psychol Med, 1-2. https://doi.org/10.1017/s0033291720000999

Bridgland, V. M. E., Moeck, E. K., Green, D. M., Swain, T. L., Nayda, D. M., Matson, L. A., . . Takarangi, M. K. T. (2021). Why the COVID-19 pandemic is a traumatic stressor. PLoS One, 16(1), e0240146. https://doi.org/10.1371/journal.pone.0240146

Brinn, A., \& Stone, J. (2020). Neutrophil-lymphocyte ratio across psychiatric diagnoses: A cross-sectional study using electronic health records. British Medical Journal Open, 10(7), e036859. https://doi.org/ 10.1136/bmjopen-2020-036859

Caamaño, W., \& L., Fuentes M, D., González B, L., Melipillán A, R., Sepúlveda C, M., \& Valenzuela G, E. . (2011). Adaptación y validación de la versión chilena de la escala de impacto de evento-revisada (EIE-R). Rev Méd Chile, 139(9), 1163-1168.

Cassiani-Miranda, C. A., Vargas-Hernández, M. C., Pérez-Aníbal, E., Herazo-Bustos, M. I., \& HernándezCarrillo, M. (2017). Confiabilidad y dimensión del cuestionario de salud del paciente (PHQ-9) para la detección de síntomas de depresión en estudiantes de ciencias de la salud en Cartagena, 2014. Biomédica, 37(Supl. 1), 112-120.

Conti, P., Ronconi, G., Caraffa, A., Gallenga, C. E., Ross, R., Frydas, I., \& Kritas, S. K. (2020). Induction of pro-inflammatory cytokines (IL-1 and IL-6) and lung inflammation by Coronavirus-19 
(COVI-19 or SARS-CoV-2): Anti-inflammatory strategies. J Biol Regul Homeost Agents, 34(2). https://doi.org/10.23812/conti-e

Dawra, S., Shrivastava, S., Chauhan, V. S., Asturkar, V., Ahmad, F., Kumar, A., . . Hasnain, S. (2021). The psychological impact of COVID-19 among newly diagnosed patients: COVID Impact study. Med J Armed Forces India, 77, S333-s337. https://doi.org/10.1016/j.mjafi.2021.05.003

Deng, J., Zhou, F., Hou, W., Silver, Z., Wong, C. Y., Chang, O., . . Z Zuo, Q. K. (2020). The prevalence of depression, anxiety, and sleep disturbances in COVID-19 patients: A meta-analysis. Ann $N Y$ Acad Sci. https://doi.org/10.1111/nyas.14506

Fois, A. G., Paliogiannis, P., Scano, V., Cau, S., Babudieri, S., Perra, R., . . Zinellu, A. (2020). The Systemic inflammation index on admission predicts in-hospital mortality in COVID-19 patients. Molecules, 25(23). https://doi.org/10.3390/molecules25235725

Garcia-Campayo, J., Zamorano, E., Ruiz, M. A., Pardo, A., Perez-Paramo, M., Lopez-Gomez, V., . . . Rejas, J. (2010). Cultural adaptation into Spanish of the generalized anxiety disorder-7 (GAD-7) scale as a screening tool. Health Qual Life Outcomes, 8, 8. https://doi.org/10.1186/1477-7525-8-8

Gennaro, M. M., Mariagrazia, P., De Lorenzo, R., Cristiano, M., Sara, P., Roberto, F., . . . Francesco, B. (2021). Persistent psychopathology and neurocognitive impairment in COVID-19 survivors: Effect of inflammatory biomarkers at three-month follow-up. Brain Behav Immun. https://doi.org/ 10.1016/j.bbi.2021.02.021

Gobierno del Perú. (2021). Sala Situacional COVID-19 Perú. Retrieved from https://covid19.minsa.gob. pe/sala_situacional.asp. Accessed 7 Aug 2021.

Gomez, J. M. D., Du-Fay-de-Lavallaz, J. M., Fugar, S., Sarau, A., Simmons, J. A., Clark, B., . . Volgman, A. S. (2021). Sex differences in COVID-19 hospitalization and mortality. $J$ Womens Health (Larchmt), 30(5), 646-653. https://doi.org/10.1089/jwh.2020.8948

Grace, A. A. (2016). Dysregulation of the dopamine system in the pathophysiology of schizophrenia and depression. Nature Reviews Neuroscience, 17(8), 524-532. https://doi.org/10.1038/nrn.2016.57

Guo, Q., Zheng, Y., Shi, J., Wang, J., Li, G., Li, C., . . . Yang, Z. (2020). Immediate psychological distress in quarantined patients with COVID-19 and its association with peripheral inflammation: A mixed-method study. Brain Behav Immun, 88, 17-27. https://doi.org/10.1016/j.bbi.2020.05.038

Hernández-Vásquez, A., Vargas-Fernández, R., Bendezu-Quispe, G., \& Grendas, L. N. (2020). Depression in the Peruvian population and its associated factors: Analysis of a national health survey. Journal of Affective Disorders, 273, 291-297. https://doi.org/10.1016/j.jad.2020.03.100

Hu, Y., Chen, Y., Zheng, Y., You, C., Tan, J., Hu, L., . . . Ding, L. (2020). Factors related to mental health of inpatients with COVID-19 in Wuhan, China. Brain Behav Immun, 89, 587-593. https:// doi.org/10.1016/j.bbi.2020.07.016

Huang, C., Huang, L., Wang, Y., Li, X., Ren, L., Gu, X., . . Cao, B. 6-month consequences of COVID19 in patients discharged from hospital: a cohort study. The Lancet. https://doi.org/10.1016/S01406736(20)32656-8

Huarcaya-Victoria, J. (2020). Consideraciones sobre la salud mental en la pandemia de COVID-19. Revista Peruana De Medicina Experimental y Salud Pública, 37(2), 327-334.

Huarcaya-Victoria, J., Meneses-Saco, A., \& Luna-Cuadros, M. A. (2020). Psychotic symptoms in COVID-19 infection: A case series from Lima, Peru. Psychiatry Research, 293, 113378-113378. https://doi.org/10.1016/j.psychres.2020.113378

Karageorgiou, V., Milas, G. P., \& Michopoulos, I. (2019). Neutrophil-to-lymphocyte ratio in schizophrenia: A systematic review and meta-analysis. Schizophrenia Research, 206, 4-12. https://doi.org/10. 1016/j.schres.2018.12.017

Kaseda, E. T., \& Levine, A. J. (2020). Post-traumatic stress disorder: A differential diagnostic consideration for COVID-19 survivors. The Clinical Neuropsychologist, 34(7-8), 1498-1514. https://doi.org/ $10.1080 / 13854046.2020 .1811894$

Kira, I. A. (2021). Taxonomy of stressors and traumas: An update of the development-based trauma framework (DBTF): A life-course perspective on stress and trauma. Traumatology. https://doi.org/ $10.1037 / \operatorname{trm} 0000305$

Kira, I. A., Alpay, E. H., Ayna, Y. E., Shuwiekh, H. A. M., Ashby, J. S., \& Turkeli, A. (2021). The effects of COVID-19 continuous traumatic stressors on mental health and cognitive functioning: A case example from Turkey. Curr Psychol, 1-12. https://doi.org/10.1007/s12144-021-01743-2

Kira, I. A., Shuwiekh, H. A. M., Ashby, J. S., Elwakeel, S. A., Alhuwailah, A., Sous, M. S. F., . . Jamil, H. J. (2021). The impact of COVID-19 traumatic stressors on mental health: Is COVID-19 a new trauma type. Int J Ment Health Addict, 1-20. https://doi.org/10.1007/s11469-021-00577-0

Kontoangelos, K., Economou, M., \& Papageorgiou, C. (2020). Mental health effects of COVID-19 pandemia: A review of clinical and psychological traits. Psychiatry Investig, 17(6), 491-505. https://doi. org/10.30773/pi.2020.0161 
Kreuter, F., \& Valliant, R. (2007). A survey on survey statistics: What is done and can be done in Stata. Symposium (international) on Combustion, 7(1), 1-21. https://doi.org/10.1177/1536867x0700700101

Kroenke, K., Spitzer, R. L., \& Williams, J. B. (2002). The PHQ-15: Validity of a new measure for evaluating the severity of somatic symptoms. Psychosomatic Medicine, 64(2), 258-266. https://doi.org/10. 1097/00006842-200203000-00008

Lee, J. H., Lee, D., Hyun, S., Hong, J. S., Kim, C. H., Kim, W., \& Sim, M. (2021). Online mental health assessments of COVID-19 patients in South Korea. Front Psychiatry, 12, 685445. https://doi.org/10. 3389/fpsyt.2021.685445

Li, X., Liu, C., Mao, Z., Xiao, M., Wang, L., Qi, S., \& Zhou, F. (2020). Predictive values of neutrophil-tolymphocyte ratio on disease severity and mortality in COVID-19 patients: A systematic review and meta-analysis. Critical Care, 24(1), 647. https://doi.org/10.1186/s13054-020-03374-8

Liu, N., Zhang, F., Wei, C., Jia, Y., Shang, Z., Sun, L., . . . Liu, W. (2020). Prevalence and predictors of PTSS during COVID-19 outbreak in China hardest-hit areas: Gender differences matter. Psychiatry Res, 287, 112921. https://doi.org/10.1016/j.psychres.2020.112921

Ma, Y. F., Li, W., Deng, H. B., Wang, L., Wang, Y., Wang, P. H., . . Xiang, Y. T. (2020). Prevalence of depression and its association with quality of life in clinically stable patients with COVID-19. J Affect Disord, 275, 145-148. https://doi.org/10.1016/j.jad.2020.06.033

Mak, I. W., Chu, C. M., Pan, P. C., Yiu, M. G., \& Chan, V. L. (2009). Long-term psychiatric morbidities among SARS survivors. General Hospital Psychiatry, 31(4), 318-326. https://doi.org/10.1016/j.genho sppsych.2009.03.001

Mazza, M. G., De Lorenzo, R., Conte, C., Poletti, S., Vai, B., Bollettini, I., . . Benedetti, F. (2020). Anxiety and depression in COVID-19 survivors: Role of inflammatory and clinical predictors. Brain Behav Immun 89, 594-600. https://doi.org/10.1016/j.bbi.2020.07.037

Mertz Schou, T., Joca, S., Wegener, G., \& Bay-Richter, C. (2021). Psychiatric and neuropsychiatric sequelae of COVID-19 - A systematic review. Brain, Behavior, and Immunity. https://doi.org/10.1016/j.bbi. 2021.07.018

Miller, A. H., Haroon, E., Raison, C. L., \& Felger, J. C. (2013). Cytokine targets in the brain: Impact on neurotransmitters and neurocircuits. Depression and Anxiety, 30(4), 297-306. https://doi.org/10.1002/ da. 22084

Moccia, L., Janiri, D., Pepe, M., Dattoli, L., Molinaro, M., De Martin, V., . . Di Nicola, M. (2020). Affective temperament, attachment style, and the psychological impact of the COVID-19 outbreak: An early report on the Italian general population. Brain Behav Iтти 87, 75-79. https://doi.org/10.1016/j.bbi. 2020.04.048

Nie, X. D., Wang, Q., Wang, M. N., Zhao, S., Liu, L., Zhu, Y. L., \& Chen, H. (2020). Anxiety and depression and its correlates in patients with coronavirus disease 2019 in Wuhan. Int J Psychiatry Clin Pract, 1-6. https://doi.org/10.1080/13651501.2020.1791345

Park, H. Y., Park, W. B., Lee, S. H., Kim, J. L., Lee, J. J., Lee, H., \& Shin, H. S. (2020). Posttraumatic stress disorder and depression of survivors 12 months after the outbreak of Middle East respiratory syndrome in South Korea. BMC Public Health, 20(1), 605. https://doi.org/10.1186/s12889-020-08726-1

Paz, C., Mascialino, G., Adana-Díaz, L., Rodríguez-Lorenzana, A., Simbaña-Rivera, K., Gómez-Barreno, L., . . . Ortiz-Prado, E. (2020). Behavioral and sociodemographic predictors of anxiety and depression in patients under epidemiological surveillance for COVID-19 in Ecuador. PLoS One, 15(9), e0240008-e0240008. https://doi.org/10.1371/journal.pone.0240008

Poyraz, B. Ç., Poyraz, C. A., Olgun, Y., Gürel, Ö., Alkan, S., Özdemir, Y. E., . . Karaali, R. (2020). Psychiatric morbidity and protracted symptoms after COVID-19. Psychiatry Res, 295, 113604-113604. https://doi.org/10.1016/j.psychres.2020.113604

Ran, L., Wang, W., Ai, M., Kong, Y., Chen, J., \& Kuang, L. (2020). Psychological resilience, depression, anxiety, and somatization symptoms in response to COVID-19: A study of the general population in China at the peak of its epidemic. Social Science and Medicine, 262, 113261-113261. https://doi.org/ 10.1016/j.socscimed.2020.113261

Raony, Í., de Figueiredo, C. S., Pandolfo, P., Giestal-de-Araujo, E., Oliveira-Silva Bomfim, P., \& Savino, W. (2020). Psycho-neuroendocrine-immune interactions in COVID-19: Potential impacts on mental health. Frontiers in Immunology, 11, 1170. https://doi.org/10.3389/fimmu.2020.01170

Rogers, J. P., Chesney, E., Oliver, D., Pollak, T. A., McGuire, P., Fusar-Poli, P., . . David, A. S. (2020). Psychiatric and neuropsychiatric presentations associated with severe coronavirus infections: A systematic review and meta-analysis with comparison to the COVID-19 pandemic. Lancet Psychiatry, 7(7), 611627. https://doi.org/10.1016/s2215-0366(20)30203-0

RosMontalbán, S., Comas Vives, A., \& Garcia-Garcia, M. (2010). Validation of the Spanish version of the PHQ-15 questionnaire for the evaluation of physical symptoms in patients with depression and/or anxiety disorders: DEPRE-SOMA study. Actas Españolas De Psiquiatría, 38(6), 345-357. 
Saldivia, S., Aslan, J., Cova, F., Vicente, B., Inostroza, C., \& Rincón, P. (2019). Propiedades psicométricas del PHQ-9 (Patient Health Questionnaire) en centros de atención primaria de Chile. Rev Méd Chile, $147,53-60$.

Seguro Social de Salud. (2020). Estadística institucional. Retrieved from http://www.essalud.gob.pe/estad istica-institucional/. Accessed 7 Aug 2021.

Spitzer, R. L., Kroenke, K., Williams, J. B., \& Lowe, B. (2006). A brief measure for assessing generalized anxiety disorder: The GAD-7. Archives of Internal Medicine, 166(10), 1092-1097. https://doi.org/10. 1001/archinte.166.10.1092

Velavan, T. P., \& Meyer, C. G. (2020). The COVID-19 epidemic. Tropical Medicine \& International Health, 25(3), 278-280. https://doi.org/10.1111/tmi.13383

Villarreal-Zegarra, D., Copez-Lonzoy, A., Bernabe-Ortiz, A., Melendez-Torres, G. J., \& Bazo-Alvarez, J. C. (2019). Valid group comparisons can be made with the Patient Health Questionnaire (PHQ-9): A measurement invariance study across groups by demographic characteristics. PLoS ONE, 14(9), e0221717. https://doi.org/10.1371/journal.pone.0221717

Wang, M., Hu, C., Zhao, Q., Feng, R., Wang, Q., Cai, H., . . Yang, Y. (2021). Acute psychological impact on COVID-19 patients in Hubei: a multicenter observational study. Transl Psychiatry, 11(1), 133. https://doi.org/10.1038/s41398-021-01259-0

Weiss, D. S., \& Marmar, C. R. (1997). The impact of event scale-Revised. In J. P. Wilson \& T. M. Keane (Eds.), Assessing psychological trauma and PTSD (pp. 399-411). Guilford Press.

World Health Organization. (2021). Coronavirus disease (COVID-19) dashboard I WHO Coronavirus Disease (COVID-19) Dashboard. Retrieved from https://covid19.who.int/?gclid=CjwKCAiAqJn9BRB 0EiwAJ1Sztem0DuIa_N2Ks2YpcEOGgyyvJIIuRLQTimQ0xkrfjR-OY0sfiF911BoC1sQQAvD_BwE. Accessed 7 Aug 2021.

Wu, T., Jia, X., Shi, H., Niu, J., Yin, X., Xie, J., \& Wang, X. (2021). Prevalence of mental health problems during the COVID-19 pandemic: A systematic review and meta-analysis. Journal of Affective Disorders, 281, 91-98. https://doi.org/10.1016/j.jad.2020.11.117

Yao, H., Chen, J. H., \& Xu, Y. F. (2020). Patients with mental health disorders in the COVID-19 epidemic. Lancet Psychiatry, 7(4), e21. https://doi.org/10.1016/s2215-0366(20)30090-0

Yuan, B., Li, W., Liu, H., Cai, X., Song, S., Zhao, J., . . . An, Y. (2020). Correlation between immune response and self-reported depression during convalescence from COVID-19. Brain Behav Immun, 88, 39-43. https://doi.org/10.1016/j.bbi.2020.05.062

Zhang, J., Yang, Z., Wang, X., Li, J., Dong, L., Wang, F., . . Zhang, J. (2020). The relationship between resilience, anxiety and depression among patients with mild symptoms of COVID-19 in China: A cross-sectional study. J Clin Nurs, 29(21-22), 4020-4029. https://doi.org/10.1111/jocn.15425

Publisher's Note Springer Nature remains neutral with regard to jurisdictional claims in published maps and institutional affiliations.

\section{Authors and Affiliations}

\section{Jeff Huarcaya-Victoria ${ }^{1,2}$ - Jessica Barreto ${ }^{2,3}$ (D) Lucia Aire LD $^{\text {(D) }}$ Angela Podestá ${ }^{\mathbb{D}} \cdot$ Mónica Caqui $^{2} \mathbb{D} \cdot$ Rosa Guija-Igreda $^{2} \cdot$ Claudia Castillo $^{2}$. Christoper A. Alarcon-Ruiz ${ }^{4}$ (D)}

1 Universidad San Ignacio de Loyola, Unidad de Investigación para la Generación y Síntesis de Evidencias en Salud, Lima, Peru

2 Departamento de Psiquiatría, Unidad de Psiquiatría de Enlace, EsSalud, Hospital Nacional Guillermo Almenara Irigoyen, Av. Grau 800, Lima, Peru

3 Facultad de Medicina de San Fernando, Universidad Nacional Mayor de San Marcos, Lima, Peru

4 Grupo de Investigacion Neurociencia, Efectividad Clínica y Salud Publica, Universidad Científica del Sur, Lima, Peru 